\title{
Siblings as a Context for Positive Development: Closeness, Communication, and Well-Being
}

\author{
Samantha LeBouef * and Jodi Dworkin
}

Department of Family Social Science, University of Minnesota, St. Paul, MN 55108, USA; jdworkin@umn.edu

* Correspondence: lebou006@umn.edu

\begin{abstract}
To address a gap in the literature we examined sibling relationships as a context for positive development. Specifically, the relationships between individual well-being, sibling closeness, and frequency of sibling communication were explored. The goal of this study was to determine whether individual well-being moderated the relationship between frequency of sibling communication and perceived sibling closeness. Participants included a subsample $(n=236)$ of youth from a larger study who reported having at least one sibling. Data were collected through Amazon's Mechanical Turk. Hierarchical multiple regression analyses revealed that associations between frequency of sibling communication and sibling closeness were statistically significant, sibling communication and closeness were highly correlated, regardless of individual differences. Neither emotional, psychological, nor social well-being moderated the relationship between frequency of sibling communication and sibling closeness. Limitations and future directions are considered.
\end{abstract}

Keywords: youth; siblings; communication; closeness; technology

Citation: LeBouef, S.; Dworkin, J. Siblings as a Context for Positive Development: Closeness, Communication, and Well-Being. Adolescents 2021, 1, 283-293. https:// doi.org/10.3390/adolescents1030021

Academic Editor: María-Jesús Cava

Received: 23 June 2021

Accepted: 15 July 2021

Published: 19 July 2021

Publisher's Note: MDPI stays neutral with regard to jurisdictional claims in published maps and institutional affiliations.

Copyright: (c) 2021 by the authors. Licensee MDPI, Basel, Switzerland. This article is an open access article distributed under the terms and conditions of the Creative Commons Attribution (CC BY) license (https:// creativecommons.org/licenses/by/ $4.0 /)$.

\section{Introduction}

Sibling relationships have been described as one of the longest, most enduring relationships in an individual's life, outlasting relationships with parents, spouses, other relatives and even friends [1]. With close sibling relationships being characterized as a source of emotional support and warmth [2], it is important to understand the sibling relationship as a unique context for positive development during critical developmental transitions. The transition out of adolescence presents an ideal opportunity for sibling research due to the many changes and transitions that siblings experience, both together and separately. During this time, there is often also a transition from the family home and no longer living with siblings; this results in sibling relationships becoming voluntary and creates a need for siblings to actively work to maintain their non-residential relationships. As young people leave home, the importance of maintaining different relationships begins to shift, and the ways in which these relationships contribute to youth development also shift. Ko and colleagues [3] suggest that even during these times of transition and re-centering of relationships, there is something unique about long-term familial bonds such that youth continue to rank seeing and spending time with family as more important than intimate relationships. This perspective suggests that youth are socially motivated to maintain the sibling relationship and that siblings are an important contributor to development [4]; however, we know little about how siblings' communication with new technologies contributes to positive development throughout adolescence and emerging adulthood.

Information and Communication Technologies (ICTs), such as smartphones, have changed the landscape of sibling relationships, creating opportunities for nearly instant connection anytime. With $100 \%$ of Americans $18-29$ years old now owning cell phones and $94 \%$ owning smartphones [5], it is important that we explore how siblings are using, or not using, these technologies to communicate with each other and the specific aspects of the sibling relationship that influence frequency of that communication. Previous research has examined many aspects of emerging adult sibling communication; however, the specific 
technological methods or modes that siblings are using to maintain their relationships have not been examined [6-10]. For example, Brockhage and Phillips [6] conducted interviews to examine how emerging adult siblings were navigating privacy management with siblings who had been living away from each other for at least a year. They addressed an important area of emerging adult sibling communication; many youth reported close relationships with their siblings and reported that they could tell their siblings anything. However, they did not explore the technologies that siblings were using to communicate. It may be that new technologies such as social media and texting allow siblings to communicate more frequently with one another, helping to keep their relationships close, and contribute to positive development even when not physically together.

\subsection{Positive Development and Sibling Contact}

As youth begin to leave home for school, work, or marriage, the relationships they previously held with their siblings begin to change. No longer is the nature of their interactions monitored by their parents or caused by sharing the same home, they now have the ability to choose how much contact they have with their siblings, or whether they have any contact at all [1,11-13]. This freedom from daily contact might cause siblings to develop, "a renewed appreciation for one another" (p. 2, [11]), which could have long-term, positive effects on the quality of their relationship [14]. Previous research suggests that two of the main motivations for contact among emerging adult and adult siblings are intimacy and comfort [15]. In a study of emerging adult siblings, Myers and Bryant [16] found that the expression of feelings and social support were how youth expressed their commitment to their siblings. Myers and colleagues [8] found that adult siblings maintain relationships through affectionate communication (i.e., verbal statements, non-verbal gestures, and social support behaviors). Thus, an increase in the number of methods of communication available with technology, and presumably an accompanying increase in the ease of communication, may result in an increase in communication frequency and ideally feelings of closeness between siblings.

\subsection{Well-Being}

Milevsky [17] explored sibling well-being and found that those who reported high social support from siblings also reported less loneliness and depression as well as significantly higher self-esteem and life satisfaction than those who reported low social support from siblings. Further, sibling social support was able to partially or completely compensate for low levels of social support from other relationships including with friends. In addition, Ko and colleagues [3] found that across a wide range of groups (U.S. college students and non-college samples from 27 countries), the motivation to maintain social relationships with family members was positively associated with psychological well-being. While these results suggest that sibling relationships can support positive psychological well-being, it is also possible that personal well-being influences these relationships.

Well-being can impact how we evaluate our relationships. Previous research reveals that emotions influence perception of messages [18] and how communication with others and support from others are experienced. For example, an individual experiencing depressive symptoms may interpret the question, "Are you still in school?" as judgmental and not a simple inquiry as intended. However, mental health or well-being is not just the absence of mental illness. A person may not be mentally ill but may not be flourishing either. In measuring emotional, psychological, and social well-being separately, the current study was designed to explore how an individual's self-reported well-being (and not simplify the absence of mental illness) impacted the relationship between frequency of sibling communication and sibling closeness. It may be that those with higher rates of emotional, psychological, and social well-being are more likely to communicate with their siblings and experience higher levels of sibling closeness. Additionally, consistent with previous research that has found belongingness in interpersonal relationships to be instrumental to 
mental health $[19,20]$, this relationship may be reversed; a close sibling relationship and more frequent communication may improve an individual's mental health.

\subsection{Communication Technologies}

When siblings are no longer living in the same home, communication is even more vital to the quality and closeness of their relationship. With the ubiquity of ICTs, it is now easier than ever to stay connected. In fact, $88 \%$ of $18-29$ year olds are social media users [21], and $100 \%$ of $18-29$ year olds own some type of cell phone [5]. Siblings have described ICTs as "paramount" for the maintenance of the sibling relationship, turning to technology-based methods for communication when one sibling left for college; less than $23 \%$ of respondents relied primarily on face-to-face communication with their siblings [22]. Continuing to explore sibling communication by examining the frequency of communication through ICTs contributes to a more comprehensive understanding of how communication using different media may be differentially associated with sibling closeness. During this time of transition, siblings who are emotionally close may prefer to maintain these relationships passively, for example, by monitoring each other's social media pages. In their 1995 study on sibling and friend closeness, Floyd and Parks [23] found that verbal behaviors and shared activities were more important for friend than for sibling closeness. Findings suggest that a more passive form of communication may be all that is needed to keep sibling relationships close, and to allow that relationship to continue to be a context for positive development. More active or frequent daily communication through text messages could be preferred to maintain feelings of closeness between siblings during this transition. Understanding the relationships between frequency of sibling communication, closeness, and well-being is essential to understanding the complexity and dynamic nature of sibling relationships.

\subsection{Present Study}

The purpose of the current study was to explore the ways in which the sibling relationship is a context for positive development and, specifically, how frequently siblings are communicating with one another, and how in-person communication and use of phone and ICTs for communication is associated with perceived sibling closeness and well-being. Previous research shows that the sibling relationship begins to make a pivotal transition as youth transition from adolescence [11]. For the first time, siblings may not be living under the same roof as one another and can control how much, if any, contact they choose to have with one another [1,10-12]. At the same time, friendships are beginning to take precedence over familial relationships [11,22], marking a critical time of change and transition for sibling relationships in particular, as they are relationships that can simultaneously be familial and egalitarian friendships. The communication patterns and relationship maintenance behaviors established during this developmental transition could dramatically influence the sibling relationship for years to come [14].

With the emergence of technologies such as texting and social networking sites, renegotiating and maintaining the sibling relationship may be easier than ever before. The current study was designed to explore how frequency of using these newer technologies, as well as previously studied communication methods (such as telephone calls), influences sibling relationships. The goal of this study was to determine whether well-being moderated the relationship between frequency of communication and perceived sibling closeness. Two research questions were considered:

RQ1: What is the relationship between frequency of sibling communication, perceived sibling closeness, and well-being (emotional, psychological, and social)?

RQ2: Does well-being (emotional, psychological, and social) moderate the relationship between frequency of sibling communication and perceived sibling closeness? 


\section{Materials and Methods}

\subsection{Participants}

The present study used a subsample ( $\mathrm{n}=236 ; 148$ female) from a larger study of youth who reported having at least one sibling. Participants age ranged from 18 to 29 , with the average age of participants being 25.2 years and the average age of siblings that participants reported on being 26.0 years. Youth take many different paths through adolescence in terms of family and education; this diversity is reflected in the current study. Educational paths also varied; $36 \%$ of participants reported having earned a 4 year degree, $33.9 \%$ reported having some college but no degree, $12 \%$ reported having a high school diploma, $6.4 \%$ had an associate or other 2 year degree, and $9.7 \%$ reported having earned a graduate or professional degree.

The sibling's participants reported on included 116 females and 120 males. The average age spacing between siblings was five years (range 1-32 years). Just under threequarters of participants identified as White (73.4\%), 8.4\% identified as Black or African American, $7.6 \%$ as Asian, $7.6 \%$ as Hispanic or Latinx, $2.1 \%$ reported more than one race, and $0.4 \%$ identified as American Indian or Alaska Native.

\subsection{Procedures}

Participants were recruited to take a 20 min online survey through Amazon Mechanical Turk (MTurk), an online labor market. This labor market is designed to match temporary work from employers or "requesters" to employees [24]. Employers are able to post jobs, known as Human Intelligence Tasks (HITs), to MTurk. Workers can then browse existing jobs and complete them in exchange for a monetary payment set by the employer. The current survey was advertised to employees on MTurk as a study that "focuses on young adult peer and family relationships and the ways that young adults use technologies in these relationships." Potential participants were asked to read through a brief description of this study including potential risks and benefits of participation, approved by the Institutional Review Board, and select either "I am 18-29 and consent to participate" or "I do not consent to participate" before beginning this study. Those who did not consent to participate were redirected to a thank you screen and were not able to complete the survey. Respondents were compensated $\$ 0.50$.

\subsection{Measures}

Participants responded to all survey questions about the sibling to which they felt emotionally closest.

\subsubsection{Perceived Sibling Closeness}

Respondents reported their perceived closeness to their closest sibling using a series of eight Likert-type scale questions designed to measure a participant's relationship with family members [25]. One question, "how often do you talk about personal things with this family member [closest sibling]?" was removed from the scale due to its strong conceptual overlap with the communication scale. Some example questions from the resulting 7-item scale include "How close are you to this family member?" and "How important is your relationship with this family member?" The response scale ranged from 1 (not at all) to 7 (very much; $\alpha=0.926 ; M=5.55, S D=1.47$ ).

\subsubsection{Frequency of Sibling Communication}

Participants reported how frequently they communicated with their closest sibling using various technologies with seven Likert-type scale questions [26]. Email and Skype were skewed such that almost none of the participants used these ICTs with their sibling, so these items were removed. The five remaining questions from the larger scale were included.

The five questions included in analyses $(\alpha=0.778)$ asked how often participants, "Talk to them in person?", "Call them on the phone?", "Send text messages to them (including 
apps like WhatsApp or Kik)?", "Send private messages to them through social media?", and "Reach out to them publicly on social media (share a link/photo with them, comment on or "like" their status updates, write on their timeline)?" The response scale ranged from 1 (Never) to 7 (Several times a day). Correlations between individual communication questions were also computed. Most correlations were greater than or equal to 0.50, suggesting that no additional information would be gained from using the individual items [27]. The mean score of the five questions was computed and used in analyses as one measure of frequency of sibling communication $(\alpha=0.778, M=3.01$, $S D=1.26)$.

\subsubsection{Well-Being}

Participants responded to questions about their well-being using the Adolescent Mental Health Continuum-Short Form, a measure of subjective well-being also described as flourishing [19]. The Mental Health Continuum was developed to measure mental health and wellness rather than mental illness. Keyes [19] argues that a person who is not mentally ill is not necessarily flourishing. This stands in contrast to previous research that tends to equate the lack of mental illness with positive development. This scale contains 14 Likerttype questions that were used to create three subscales-emotional well-being (3 questions), for example, "During the past 30 days how often did you feel happy?" $(\alpha=0.865 ; M=4.68$, $S D=1.00)$; psychological well-being (6 questions), for example, "During the past 30 days how often did you feel that you liked most parts of your personality?" $(\alpha=0.913 ; M=4.49$, $S D=1.12$ ); and social well-being (5 questions), for example, "How often did you feel that you had something important to contribute to society?" $(\alpha=0.869 ; M=3.79, S D=1.19)$. Response options ranged from 1 (Never) to 6 (Every day).

\subsubsection{Internalizing and Externalizing}

Measures of internalizing and externalizing behaviors were included as control variables. A participant's emotional state has been shown to bias their responses to survey items and in turn lead to an inflation of associations between variables [28]. For this study, these measures were used to control for the internalizing and externalizing behaviors of the reporting sibling to ensure that participants' positive or negative affect did not account for the relationships that emerged. Internalizing and externalizing were measured using the Strengths and Difficulties Questionnaire-Adolescent report (SDQ [29]). Computing internalizing and externalizing scales is suggested for assessing the broad constructs among low-risk samples [30]. This measure consists of 25 questions separated into three scales: internalizing behaviors (10 questions), for example, "I would rather be alone than with other people," ( $\alpha=0.709 ; M=1.74, S D=0.370)$, and externalizing behaviors (10 questions), for example, "I am restless, I find it hard to sit down for long," $(\alpha=0.704 ; M=1.51, S D=0.316)$. The five remaining questions assessed prosocial behaviors. However, that scale was not utilized for this study. Participants responded using a Likert-type scale that ranged from 1 (Not true) to 3 (Certainly true).

\subsubsection{Demographic Control Variables}

Previous sibling research has found significant, although sometimes mixed, associations between race, gender, age and sibling relationships. In the current study, descriptive statistics revealed that race, gender, age, and living with the sibling were significantly associated with sibling closeness and frequency of communication in this study. Therefore, age of the sibling and participant as well as participant gender were used as controls, with male coded as 1 and female as 2 . Second, frequency of communication and sibling closeness may be impacted by sharing a residence, as siblings who live together may be in communication more frequently in person, potentially skewing communication technology results. Therefore, residing with a sibling (yes or no) for the past 12 months was controlled. Last, participants reported their race as either American Indian or Alaska Native (1), Asian (2), Black or African American (3), Native Hawaiian or Other Pacific Islander (4), Caucasian (5), Hispanic or Latinx (6), mixed race (7), don't know or prefer not to answer (8), or other (9). 
Participants also reported on marital status, whether they had children, their parents' marital status, the last grade they completed in school, their school status over the last twelve months (enrolled in school full time, enrolled in school part time, on leave, or not in school), what degree they were seeking to obtain, work status over the past twelve months (full time, part time, unemployed/looking, or unemployed/not looking), and annual gross income. Separate tests ( $T$-tests and ANOVAs) were run for each of these demographic and family structure variables to explore differences among variables of interest (closeness, frequency of communication, psychological, social, and emotional well-being) and no statistically significant differences were found.

\subsection{Missing Data}

Missing data were found for all five communication variables. Little's MCAR test was run to test the hypothesis that data were missing completely at random; this assumption must be met prior to replacing missing values with imputation techniques. Results from Little's MCAR test revealed that the data were missing completely at random $\left(\chi^{2}=7.09\right.$, $d f=8, p=0.527)$. Since the amount of missing data was less than $2 \%$ for all five communication questions $(0.4 \%$ to $1.3 \%)$, expectation maximization (EM) was used to handle the missing data. Missing data were also found for the internalizing and externalizing variables, emotional well-being, social well-being, and sibling closeness. Results from Little's MCAR test showed that the missing data were not missing completely at random $\left(\chi^{2}=35.5\right.$, $d f=20, p=0.018$ ). Inspection of the data revealed very little missing data within each scale $(0.4 \%$ to $1.7 \%)$. T-tests and chi-square tests revealed no significant differences between participants with missing data and those with complete data for any study variables. With so little missing data and no meaningful differences between participants, missing data were also handled through EM procedures.

\subsection{Moderation Testing}

Before testing for moderation (RQ2), the data were evaluated to determine whether the three assumptions of moderation were met; relationships between predictors and dependent variables were linear, residuals were normally distributed, and correct causal ordering was examined [27]. Analyses were then computed using IBM SPSS Statistics 25. First, the predictor variable, frequency of sibling communication, as well as each of the moderation variables (emotional, psychological, and social well-being) were standardized to allow comparison of measures on the same scale. Next, the standardized frequency of communication scale was multiplied by each of the standardized well-being variables to form three interaction terms.

Three regressions were then computed, one with each potential moderator (emotional, psychological, and social well-being). In the first step, the regression models were fit with frequency of communication and well-being (either emotional, psychological, or social). In the second step, control variables were entered which included age of the participant, age of the sibling, race, gender, living with a sibling, as well as internalizing and externalizing behaviors. Last, the interaction term between frequency of communication and each of the well-being variables was added to the regression model. The interaction plot and the change in $R^{2}$ were examined to determine the proportion of variance in sibling closeness accounted for by frequency of communication and well-being to determine whether well-being moderated the relationship between frequency of sibling communication and closeness.

\section{Results}

To test our first research question exploring the associations between frequency of sibling communication, sibling closeness and emotional, psychological, and social wellbeing, correlations were computed (see Table 1). Frequency of sibling communication and sibling closeness were significantly correlated, $\mathrm{r}(236)=0.529, p=0.000$. Frequency of sibling communication was positively correlated with all three measures of well-being: emotional well-being, $\mathrm{r}(236)=0.196, p=0.000$, psychological well-being, $\mathrm{r}(236)=0.238$, 
$p=0.000$, and social well-being, $\mathrm{r}(236)=0.203, p=0.000$. Perceived sibling closeness was also positively correlated with emotional well-being, $\mathrm{r}(236)=0.211, p=0.001$ and psychological well-being, $\mathrm{r}(236)=0.223, p=0.001$ but was not significantly correlated with social well-being, $\mathrm{r}(236)=0.121, p=0.064$.

Table 1. Means, Standard Deviations, and Correlations of Model Variables.

\begin{tabular}{|c|c|c|c|c|c|c|c|c|c|c|c|}
\hline \multirow[t]{2}{*}{ Variables } & \multirow[t]{2}{*}{ Mean } & \multirow[t]{2}{*}{ SD } & \multicolumn{9}{|c|}{ Correlations } \\
\hline & & & 1 & 2 & 3 & 4 & 5 & 6 & 7 & 8 & 9 \\
\hline 1 Sibling Closeness & 5.55 & 1.47 & - & & & & & & & & \\
\hline $\begin{array}{l}2 \text { Frequency of } \\
\text { Sibling Communication }\end{array}$ & 3.01 & 1.26 & $0.529 * *$ & - & & & & & & & \\
\hline 3 Psychological Well-Being & 4.49 & 1.12 & $0.223 * *$ & $0.238 * *$ & - & & & & & & \\
\hline 4 Social Well-Being & 3.79 & 1.19 & 0.121 & $0.203^{* *}$ & $0.740 * *$ & - & & & & & \\
\hline 5 Emotional Well-Being & 4.68 & 1.00 & $0.211 * *$ & 0.196 ** & $0.826 * *$ & $0.667 * *$ & - & & & & \\
\hline 6 Internalizing & 1.74 & 0.370 & $-0.169 * *$ & $-0.168^{* *}$ & $-0.378 * *$ & $-0.377 * *$ & $-0.409 * *$ & - & & & \\
\hline 7 Externalizing & 1.51 & 0.316 & -0.115 & -0.070 & $-0.244^{* *}$ & $-0.168^{* *}$ & $-0.302 * *$ & $0.477^{* *}$ & - & & \\
\hline 8 Age of Participant & 25.13 & 2.84 & -0.024 & 0.013 & 0.020 & -0.067 & -0.012 & 0.029 & -0.006 & - & \\
\hline 9 Age of Sibling & 26.03 & 6.40 & -0.056 & -0.091 & -0.011 & 0.033 & -0.073 & -0.059 & -0.40 & $0.333 * *$ & - \\
\hline
\end{tabular}

Note. ${ }^{* *} p<0.001$. Closeness response scale ranged from 1 (Not at all) to 7 (Very much). Communication response scale ranged from 1 (Never) to 7 (Several times a day). Well-being response scales ranged from 1 (Never) to 6 (Every day). Internalizing and externalizing response scales ranged from 1 (Not true) to 3 (Certainly true).

\subsection{Emotional Well-Being}

Emotional well-being was tested as a moderator of the relationship between frequency of sibling communication and perceived sibling closeness. The full model was statistically significant, $\mathrm{F}(13,222)=8.61, p=0.000$. Frequency of communication was significantly associated with sibling closeness in the full model $(\beta=0.498, \mathrm{t}(236)=8.13 p=0.000)$; emotional well-being was not significant. None of the control variables were significant in the full model. The interaction term between emotional well-being and frequency of communication was also not significant $(\beta=-0.023, p=0.697)$ and did not account for significantly more variance in perceived sibling closeness, $\Delta R^{2}=0.000, F(1,222)=0.152$, $p=0.697$, beyond emotional well-being and frequency of communication.

\subsection{Psychological Well-Being}

Psychological well-being was tested as a moderator of the relationship between frequency of sibling communication and perceived sibling closeness. The full model was statistically significant, $\mathrm{F}(13,222)=8.54, p=0.000$. Frequency of communication was significantly associated with sibling closeness in the full model $(\beta=0.494, \mathrm{t}(236)$ $=8.02, p=0.000)$. None of the control variables were significant in the full model. The interaction term between psychological well-being and frequency of communication was not significant $(\beta=-0.021, p=0.717)$ and did not account for significantly more variance in perceived sibling closeness, $\Delta \mathrm{R}^{2}=0.000, \mathrm{~F}(1,222)=0.132, p=0.717$, beyond psychological well-being and frequency of communication.

\subsection{Social Well-Being}

Social well-being was tested as a moderator of the relationship between frequency of sibling communication and perceived sibling closeness. The full model was statistically significant, $\mathrm{F}(13,222)=8.41, p=0.000$. Frequency of communication was significantly associated with sibling closeness in the full model $(\beta=0.513, \mathrm{t}(236)=8.41, p=0.000)$. None of the control variables were significant in the full model. The interaction term between social well-being and frequency of communication was not significant $(\beta=-0.040$, $p=0.507)$ and did not account for significantly more variance in perceived sibling closeness, $\Delta \mathrm{R}^{2}=0.001, \mathrm{~F}(1,222)=0.441, p=0.507$, beyond social well-being and frequency of communication.

\section{Discussion}

This study was designed to explore sibling relationships as a context for positive development, specifically sibling relationship closeness, and frequency of communication, 
emotional, psychological, and social well-being. Sibling relationships are one of the longest relationships in an individual's life, outlasting those with parents and peers. Siblings grow up with us, they share our insider knowledge of the family unit; they know exactly how to irritate us, and each sibling relationship is as unique as the individuals who make up those relationships. Extending the sibling literature to explore more about the factors that influence these lifelong relationships is critical for understanding what qualities of the individuals and dyads makes these relationships so enduring and what qualities contribute to positive development or sibling closeness.

\subsection{Frequency of Sibling Communication, Sibling Closeness and Well-Being}

Several studies [2,12] have found that, even though late adolescent and young adult siblings are spending less time together than siblings at younger ages, close sibling relationships have been found to have more "emotional exchanges, such as discussing personal matters, and feeling more warmth toward their siblings" in young adulthood than in adolescence (p. 82, [12]). Consistent with this, results from the current study revealed that frequency of sibling communication was associated with perceived sibling closeness. Participants communicated with their closest sibling relatively infrequently $(M=3.02)$, only every few weeks, and still considered themselves close $(M=5.55)$. Communication rates remained low even though the measure of communication included in person, phone calls, text messages, and social media. These findings suggest that despite infrequent daily communication during late adolescence and young adulthood, siblings are still an important source of support and advice for each other. This more inclusive measure of communication frequency paints a more complete picture of the sibling relationship and the variety of ways siblings support and encourage one another to achieve their goals. Future research should explore the content of sibling messages and how what is communicated during these fairly infrequent interactions is related to feelings of perceived sibling closeness and sibling support of one another; it is reasonable that the tone and content of the communication may be more important than simply the amount of time siblings spend communicating with one another.

Frequency of sibling communication was also positively associated with all three types of well-being. However, because the current study is cross sectional, it cannot be determined whether more frequent communication causes increased well-being or whether increased well-being causes siblings to communicate more; perhaps both are true. For instance, the perceived rewards and costs of the relationship could impact well-being and as a result lead to increases or decreases in communication. Alternatively, more frequent or less frequent communication could also impact well-being. Results of the current study further our understanding of sibling relationships and provide direction for future research, suggesting the need to explore the ways in which sibling relationships are related to both positive well-being and poor mental health.

Although emotional, psychological, and social well-being did not affect the direction or strength of the relationship between frequency of sibling communication and sibling closeness, all three types of well-being were significantly associated with frequency of sibling communication and sibling closeness. Since participants reported on their closest siblings, they were likely to have already identified the relationship as positive and there may be little fluctuation in their feelings of closeness due to well-being. In fact, when siblings are close, low well-being could lead siblings to seek support from each other, potentially explaining the association between well-being, communication, and closeness.

\subsection{Limitations and Future Directions}

Though previous studies have examined sibling relationships, this study extended the literature by considering the use of various technologies in sibling communication during the transition from adolescence. However, several limitations need to be considered. First, these data were cross sectional. Therefore, although results revealed associations between frequency of sibling communication, well-being, and closeness, causation cannot 
be determined. Future studies should utilize a longitudinal approach to understanding changes in sibling communication and closeness over time. Second, surveys were completed by only one member of the sibling dyad. There is much to learn from reports from all siblings in a given family in order to understand different relationship perceptions and how those perceptions impact relationship quality. Additionally, future studies should consider exploring differences between those young people with siblings and those without siblings.

While including ICTs used for communication is a strength of the current study, the measures focused on frequency of communication. Future research should examine the content of the messages that are communicated; different technologies are used to send different types of messages. For example, the content of messages posted publicly on social media sites may be very different from what is said in a private message between siblings. Therefore, investigating various forms of communication could help determine how the content of messages impacts feelings of closeness.

Research on sibling relationships has predominately focused on white samples, with the current sample nearly three-quarters (73.3\%) white. In their review of sibling literature, McHale and colleagues [31] identified several studies on African American siblings [32-35] and several on Mexican American families [36-38], concluding that cultural factors influence sibling relationships. McHale and colleagues [31] called for more cross-cultural research of sibling relationships; future research should include more diverse samples. Even though there were more than $25 \%$ youth of color in the present study, the percent of African American youth for example may have been too small to detect differences.

An extensive amount of research has been conducted on sibling birth order. These studies have focused on characteristics of each birth position and differential treatment of siblings by parents [31]. It is suggested that differential treatment of siblings stems from the first-born child receiving more attention and resources from parents than subsequent children [31]. Previous findings from sibling research is mixed when it comes to sibling age and gender dyads. Some studies have found that both age and gender were significant in influencing various aspects of the sibling relationship, other studies have found only one or neither to be significant. In the current study, neither sibling nor participant age were significantly associated with sibling closeness. This demonstrates a need for further exploration of the sibling relationships and the variables that may influence these lifelong relationships.

Siblings have been a neglected relationship in the youth development literature. Findings from the current study suggest the need for youth workers to further consider the ways in which siblings can be either a support or hinderance to youth development experiences from adolescence. Future questions might consider: Should siblings be part of the same youth development programs regardless of age or gender? If siblings are in different programs, should there be some parallel teaching so they are receiving similar content? Should siblings be taught when to be concerned about their sibling and how to intervene? How can siblings be taught to communicate productively with one another?

Author Contributions: Conceptualization, J.D. and S.L.; Methodology, J.D. and S.L.; Software, J.D.; Validation, J.D. and S.L.; Formal Analysis, S.L.; Writing-Original Draft Preparation, S.L.; WritingReview and Editing, J.D.; Supervision, J.D.; Funding Acquisition, J.D. All authors have read and agreed to the published version of the manuscript.

Funding: This study was supported by funding from the Minnesota Agricultural Experiment Station to the second author.

Institutional Review Board Statement: This study was conducted according to the guidelines of the Declaration of Helsinki and approved by the Institutional Review Board (or Ethics Committee) of University of Minnesota (protocol code 1606S89423, Initial approval 5/17/2017).

Informed Consent Statement: Informed consent was obtained from all subjects involved in this study.

Data Availability Statement: The data presented in this study are not publicly available. The second author can provide additional information. 
Conflicts of Interest: The authors declare no conflict of interest. The funders had no role in the design of the study; in the collection, analyses, or interpretation of data; in the writing of the manuscript, or in the decision to publish the results.

\section{References}

1. Conger, K.J.; Cicirelli, V.G. Sibling relationships across the life Span. J. Marriage Fam. 1996, 58, 804. [CrossRef]

2. Cicirelli, V.G. A comparison of college women's feelings toward their siblings and parents. J. Marriage Fam. 1980, 42, 111-118. Available online: https:/ /www.jstor.org/stable/351939 (accessed on 23 June 2021). [CrossRef]

3. Ko, A.; Pick, C.; Kwon, J.Y.; Barlev, M.; Krems, J.A.; Varnum, M.E.W.; Neel, R.; Peysha, M.; Boonyasiriwat, W.; Brandstätter, E.; et al. Family matters: Rethinking the psychology of human social motivation. Perspect. Psychol. Sci. 2020, 15, 173-201. [CrossRef] [PubMed]

4. Feinberg, M.E.; Solmeyer, A.R.; Hostetler, M.L.; Sakuma, K.-L.; Jones, D.; McHale, S.M. Siblings are special: Initial test of a new approach for preventing youth behavior problems. J. Adolesc. Health 2013, 53, 166-173. [CrossRef]

5. Pew Research Center. Mobile Fact Sheet; Pew Research Center: Washington, DC, USA, 2018; Available online: http://www. pewinternet.org/fact-sheet/mobile/ (accessed on 23 June 2021).

6. Brockhage, K.; Phillips, K.E. (Re)Negotiating our relationship: How contradictions emerge in sibling privacy boundaries. South. Commun. J. 2016, 81, 79-91. [CrossRef]

7. Myers, S.A.; Bryant, L.E. Emerging adult siblings' use of verbally aggressive messages as hurtful messages. Commun. Q. 2008, 56, 268-283. [CrossRef]

8. Myers, S.A.; Byrnes, K.A.; Frisby, B.N.; Mansson, D.H. Adult siblings' use of affectionate communication as a strategic and routine relational maintenance behavior. Commun. Res. Rep. 2011, 28, 151-158. [CrossRef]

9. Myers, S.A.; Odenweller, K.G. The use of relational maintenance behaviors and relational characteristics among sibling types. Commun. Stud. 2014, 66, 238-255. [CrossRef]

10. Schrodt, P.; Phillips, K.E. Self-disclosure and relational uncertainty as mediators of family communication patterns and relational outcomes in sibling relationships. Commun. Monogr. 2016, 83, 486-504. [CrossRef]

11. Conger, K.J.; Little, W.M. Sibling relationships during the transition to adulthood. Child Dev. Perspect. 2010, 4, 87-94. [CrossRef]

12. Scharf, M.; Shulman, S.; Avigad-Spitz, L. Sibling relationships in emerging adulthood and in adolescence. J. Adolesc. Res. 2005, 20, 64-90. [CrossRef]

13. Stocker, C.M.; Lanthier, R.P.; Furman, W. Sibling relationships in early adulthood. J. Fam. Psychol. 1997, 11, 210-221. [CrossRef]

14. White, L. Sibling Relationships over the life course: A panel analysis. J. Marriage Fam. 2001, 63, 555-568. [CrossRef]

15. Fowler, C. Motives for sibling communication across the lifespan. Commun. Q. 2009, 57, 51-66. [CrossRef]

16. Myers, S.A.; Bryant, L.E. The use of behavioral indicators of sibling commitment among emerging adults. J. Fam. Commun. 2008, 8, 101-125. [CrossRef]

17. Milevsky, A. Compensatory patterns of sibling support in emerging adulthood: Variations in loneliness, self-esteem, depression and life satisfaction. J. Soc. Pers. Relatsh. 2005, 22, 743-755. [CrossRef]

18. Clore, G.L.; Huntsinger, J.R. How emotions inform judgment and regulate thought. Trends Cogn. Sci. 2007, 11, 393-399. [CrossRef]

19. Keyes, C.L.M. Mental illness and/or mental health? Investigating axioms of the complete state model of health. J. Consult. Clin. Psychol. 2005, 73, 539-548. [CrossRef]

20. Reis, H.T.; Gable, S.L. Toward a positive psychology of relationships. In Flourishing: Positive Psychology and the Life Well-Lived; Keyes, C.L.M., Haidt, J., Eds.; American Psychological Association: Washington, DC, USA, 2003; pp. $129-159$.

21. Pew Research Center. Social Media Fact Sheet; Pew Research Center: Washington, DC, USA, 2018; Available online: http: / / www.pewinternet.org/fact-sheet/social-media / (accessed on 23 June 2021).

22. Lindell, A.K.; Campione-Barr, N.; Killoren, S.E. Technology-mediated communication with siblings during the transition to college: Associations with relationship positivity and self-disclosure. Fam. Relat. 2015, 64, 563-578. [CrossRef]

23. Floyd, K.; Parks, M.R. Manifesting closeness in the interactions of peers: A look at siblings and friends. Commun. Rep. 1995, 8, 69-76. [CrossRef]

24. Dworkin, J.; Hessel, H.; Gliske, K.; Rudi, J.H. A comparison of three online recruitment strategies for engaging parents. Fam. Relat. 2016, 65, 550-561. [CrossRef] [PubMed]

25. Vangelisti, A.L.; Caughlin, J.P. Revealing family secrets: The influence of topic, function, and relationships. J. Soc. Pers. Relatsh. 1997, 14, 679-705. [CrossRef]

26. Lenhart, A.; Purcell, K.; Smith, A.; Zickuhr, K. Social Media \& Mobile Internet Use among Teens and Young Adults. Pew Internet \& American Life Project. 2010. Available online: http:/ /www.pewinternet.org/2010/02/03/social-media-and-young-adults / (accessed on 23 June 2021).

27. Leech, N.L.; Barrett, K.C.; Morgan, G.A. IBM SPSS for Intermediate Statistics: Use and Interpretation; Routledge: New York, NY, USA, 2015.

28. Rueter, M.A.; Connor, J.J.; Pasch, L.; Anderson, K.N.; Scheib, J.; Koerner, A.F.; Damario, M. Sharing information with children conceived using in vitro fertilisation: The effect of parents' privacy orientation. J. Reprod. Infant Psychol. $2016,34,90-102$. [CrossRef] 
29. Goodman, R. The strengths and difficulties questionnaire: A research note. J. Child Psychol. Psychiatry 1997, 38, 581-586. [CrossRef] [PubMed]

30. Goodman, A.; Lamping, D.L.; Ploubidis, G.B. When to use broader internalising and externalising subscales instead of the hypothesised five subscales on the Strengths and Difficulties Questionnaire (SDQ): Data from British parents, teachers and children. J. Abnorm. Child Psychol. 2010, 38, 1179-1191. [CrossRef] [PubMed]

31. McHale, S.M.; Updegraff, K.A.; Whiteman, S. Sibling relationships and influences in childhood and adolescence. J. Marriage Fam. 2012, 74, 913-930. [CrossRef]

32. Brody, G.H.; Ge, X.; Kim, S.Y.; Murry, V.M.; Simons, R.L.; Gibbons, F.X.; Gerrard, M.; Conger, R.D. Neighborhood disadvantage moderates associations of parenting and older sibling problem attitudes and behavior with conduct disorders in African American children. J. Consult. Clin. Psychol. 2003, 71, 211-222. [CrossRef]

33. Brody, G.H.; Kim, S.; Murry, V.M.; Brown, A.C. Longitudinal direct and indirect pathways linking older sibling competence to the development of younger sibling competence. Dev. Psychol. 2003, 39, 618-628. [CrossRef]

34. East, P.L.; Reyes, B.T.; Horn, E.J. Association between adolescent pregnancy and a family history of teenage births. Perspect. Sex. Reprod. Health 2007, 39, 108-115. [CrossRef] [PubMed]

35. McHale, S.M.; Whiteman, S.D.; Kim, J.; Crouter, A.C. Characteristics and correlates of sibling relationships in two-parent African American families. J. Fam. Psychol. 2007, 21, 227-235. [CrossRef]

36. Gamble, W.C.; Modry-Mandell, K. Family relations and the adjustment of young children of Mexican descent: Do family cultural values moderate these associations? Soc. Dev. 2008, 17, 358-379. [CrossRef]

37. Killoren, S.E.; Thayer, S.M.; Updegraff, K.A. Conflict resolution between Mexican origin adolescent siblings. J. Marriage Fam. 2008, 70, 1200-1212. [CrossRef] [PubMed]

38. Updegraff, K.A.; McHale, S.M.; Whiteman, S.D.; Thayer, S.M.; Delgado, M.Y. Adolescent sibling relationships in Mexican American families: Exploring the role of familism. J. Fam. Psychol. 2005, 19, 512-522. [CrossRef] [PubMed] 